\title{
Computed tomography of the uterus and ovaries in healthy dogs: a descriptive and comparative study
}

\author{
Computertomografie van de uterus en ovaria bij gezonde teven: \\ een beschrijvende en vergelijkende studie
}

\author{
S. Vermeire, M. Brzozowska, M. Rapp
}

\begin{abstract}
${ }^{1}$ Department of Diagnostic Imaging, Evidensia Small Animal Referral Hospital Strömsholm, Djursjukhusvägen 11, 73494 Strömsholm, Sweden
\end{abstract}

simon.vermeire@evidensia.se

\begin{abstract}
A
BSTRACT

Canine uterine and ovarian diseases are common in countries where prophylactic ovariohysterectomy is not generally performed and clinical work-up is commonly confined to ultrasonography of the female reproductive tract. Although increasingly used in veterinary practice, there is a lack of computed tomography (CT) data on either the normal or abnormal appearance of these organs. In this prospective, descriptive and comparative study, CT images of the uterus and ovaries of 22 bitches with no clinical signs of reproductive organ disease were examined. CT was compared to ultrasonography and the level of agreement between both was analyzed. The results indicate that it is feasible to evaluate the entire uterus and ovaries using CT. In this study, a range of cervical, uterine horn and ovarian appearances are described and illustrated. Although native CT failed to detect uterine cystic lesions, other CT characteristics were linked to cystic endometrial hyperplasia, warranting ultrasonographic examination. In general, CT can be used to approximate ultrasonographic measurements.
\end{abstract}

\section{SAMENVATTING}

Aandoeningen van de uterus en ovaria bij de hond zijn veelvoorkomend in landen waar profylactische ovariohysterectomie niet systematisch wordt uitgevoerd. Voornamelijk echografie wordt gebruikt om deze organen in beeld te brengen. Hoewel computertomografie (CT) een steeds vaker voorkomende techniek is, ontbreken er studies die de normale en pathologische uterus en ovaria beschrijven met behulp van deze beeldvormingstechniek. In deze prospectieve, beschrijvende en vergelijkende studie werden de uterus en ovaria van 22 honden zonder urogenitale symptomen onderzocht met behulp van $\mathrm{CT}$ en vervolgens echografie. In de studie wordt aangetoond dat CT kan gebruikt worden om de volledige uterus en ovaria te beoordelen. Bovendien worden verschillende variaties van beide organen beschreven en geïllustreerd. Hoewel cysteuze veranderingen van de uterus niet werden gedetecteerd met behulp van CT zonder contrast, werden andere CT-kenmerken gelinkt aan cysteuze endometriumhyperplasie. Doorgaans benaderen CT-metingen van de uterus en ovaria de metingen uitgevoerd door middel van echografie.

\section{INTRODUCTION}

For many decades, canine uterine and ovarian disorders have been routinely investigated using ultrasonography, especially in countries where prophylactic ovariohysterectomy is not generally performed (Dow, 1959; Poffenbarger and Feeney, 1986; Kähn, 1994;
Nyland et al., 2002). The most commonly encountered canine uterine disorders are cystic endometrial hyperplasia (CEH), hydrometra, mucometra, and pyometra (Hagman, 2014; Veiga et al., 2017). While the clinical signs of pyometra are often obvious, $\mathrm{CEH}$ and hydro/ mucometra may be subclinical but may nevertheless contribute to decreased fertility and pyometra (Eng- 
land et al., 2003; Hagman, 2014). Common ovarian disorders include cysts and neoplasia (England et al., 2003, Arlt and Haimerl, 2016).

The canine uterus comprises a cervix, a short body and two uterine horns. The uterine wall can be divided histologically into three tunicae: the inner mucosal endometrium containing the uterine glands, the middle muscular myometrium and the peripheral serosal perimetrium. The myometrium can be further divided into inner circular and outer longitudinal muscle layers (Evans and de Lahunta, 2013). The uterine arterial blood supply is delivered by the uterine ramus of the vaginal artery, and to a lesser extent by the uterine ramus of the ovarian artery. The arterial branches penetrate the uterine wall and form a circumferential stratum vasculare between the two muscle layers (Augsburger and Kürzi, 2004). The corresponding venous rami form the main venous supply (Schummer et al., 1981).

Ultrasonographic imaging of the uterus shows significant variability, depending on the animal's size, number of previous pregnancies and concomitant disease, as well as the stage of the estrous cycle (Davidson and Baker, 2009; Freitas et al., 2017). Changes related to the latter are most prominent during proestrus and early estrus, during which the uterine diameter increases and a thin hyperechoic line or minimal amount of anechoic fluid may be seen in the lumen. Wall layering also becomes more distinct, and ultrasonography can identify a hypoechoic inner layer (endometrium and myometrium) and a hyperechoic outer layer (perimetrium) (England et al., 2003; Freitas et al., 2017). Additionally, as the cervix enlarges, transverse scanning reveals multiple layers resembling a 'bullseye' (Yeager and Concannon, 1995). Like the uterus, ovaries may vary in size, shape, homogeneity and presence of follicles at different stages of the estrous cycle (Silva et al., 1996; Davidson and Baker, 2009).

With the increased availability and use of computed tomography $(\mathrm{CT})$ in veterinary practice, there is a need for corresponding reference data. However, a systematic search of Pubmed bibliographic databases revealed a lack of studies describing the computed tomographic appearance (native or contrast enhanced) of the canine uterus and ovaries and its common pathologies.

The aim of this prospective study was to describe the CT appearance of the ovaries and uterus in bitches with no clinical history of reproductive organ disease. The study also evaluated CT's ability to detect cystic and intraluminal uterine changes and ovarian abnormalities and by these means, the utility of native or contrast-enhanced CT in detecting subclinical reproductive organ disease. Finally, the study assessed the level of agreement between multiple ultrasonographic (US) and computed tomographic measurements. It was hypothesized that the two diagnostic imaging modalities would show good agreement in relation to measurement but that US would be superior in de- tecting luminal content, wall layering and cystic wall changes.

\section{METHODS AND MATERIALS}

\section{Case selection}

This prospective, descriptive and comparative study was performed at the Evidensia Small Animal Referral Hospital Strömsholm, Sweden, between March 2019 and March 2020. The sample included client-owned intact female adult dogs, whose clinical symptoms warranted CT examination, with or without intravenous contrast medium administration. Dogs presenting with urogenital symptoms at the time of examination were excluded. Owner consent was obtained before enrollment in the study, and ethical approval was obtained from the regional governmental ethical committee (Jordbruksverket, Uppsala, Sweden) before the study commenced (Nr. 001558).

All dogs were fasted for at least twelve hours before consecutive CT examination, US examination and vaginal cytological sampling under sedation or general anesthesia.

\section{Imaging analysis}

The dogs were placed in ventral or dorsal recumbency for helical CT acquisition using a 40-slice CT scanner (Philips Brilliance 40, Philips Medical Systems, the Netherlands) with the following settings: soft tissue algorithm; slice thickness $2 \mathrm{~mm}$; slice gap 1mm; voltage 80-120 kVp; current 250-313 mA; matrix 512 x 512. Intravenous contrast medium (Optiray $300 \mathrm{mg} \mathrm{I} / \mathrm{ml}, 600 \mathrm{mg} \mathrm{I} / \mathrm{kg}$ bodyweight), administered using a power injector (Liebel-Flarsheim, Ohio, US), was only used if required based on the clinical (non-urogenital) presentation. Using Horos viewing software (v.3.3.6., Horosproject.org) for multiplanar reconstruction of $\mathrm{CT}$ acquisitions, the uterine horns were aligned on their long axis before measuring their diameter in all three planes. The ovaries were similarly aligned for measurement of long-axis length. The window level and width were set at 60 and 300 (default abdominal setting), respectively, and adapted where necessary.

With the dogs placed in ventral recumbency, US examinations were performed by a senior ECVDI resident (S.V.), using one of two identical ultrasound machines (Logic E9, GE Healthcare, Wisconsin, US). In most instances, the abdominal hair was wiped and flattened with alcohol prior to scanning, although hair clipping was occasionally performed. Ultrasound gel was used in all cases. Using a broad spectrum (9-11 $\mathrm{MHz}$ ) linear transducer for small and middle-sized dogs and a broad spectrum (6-10 MHz) microconvex transducer for larger dogs, still images and cine-loops were acquired of the cervix, corpus, uterine horns and ovaries. 


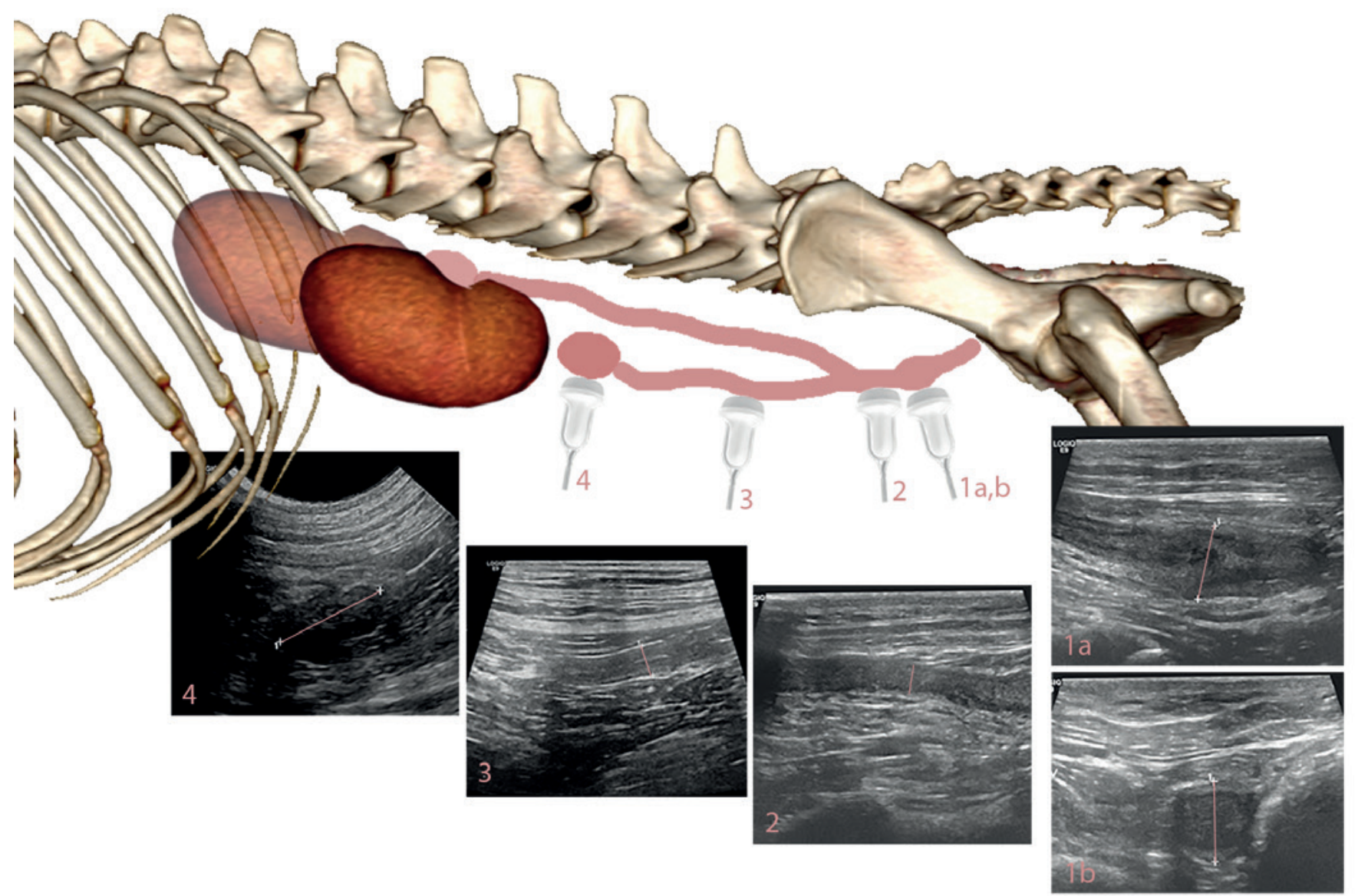

Figure 1. Schematic presentation of acquired ultrasonographic images of the cervix (1a longitudinal plane, 1b transverse plane), 2. body, 3. uterine horns and 4. ovaries.

US measurements were performed as shown in Figure 1. The cervix diameter was measured in longitudinal and transverse planes (Figures $1 \mathrm{a}$ and $1 \mathrm{~b}$, respectively). Given the tortuosity of the corpus and especially both uterine horns, these structures were measured only in the longitudinal plane, tilting the transducer as far as necessary to capture the longest possible longitudinal segment. The long-axis length of both ovaries was also measured. As the uterine horns frequently lie between or adjacent to intestinal loops that would compromise measurement accuracy, measurements were obtained from regions where there was no such contact rather than from a fixed measurement location. Intraluminal fluid (yes/no), cystic wall lesions (yes/no), and ovarian cyst-like structures (yes/ no; if yes, how many) were also recorded in both imaging modalities, documenting any computed tomographic hypoattenuated areas in Hounsfield units. US measurement data were acquired from still images or loops using local PACS viewing software (IDS7, Sectra AB, Linköping, Sweden).

\section{Vaginal cytological analysis}

Cytological samples were collected from the cranial vagina of laterally recumbent dogs using a sterile cotton-tipped applicator moistened with sterile water.
After rolling the applicator onto glass slides, air-drying and Diff-Quik ${ }^{\mathrm{TM}}$ staining, microscopic analysis of the samples was performed by onsite laboratory biomedical scientists to categorize the dogs as being in proestrus, estrus, metestrus or anestrus (Solano-Gallego and Masserdotti, 2015).

\section{Statistical analysis}

In a retrospective pre-experiment, the mean and standard deviation of differences between US and CT measurements were calculated. To assess agreement between the two methods of measurement, a BlandAltman plot was used to calculate a sample size providing $90 \%$ power (Lu et al., 2016). The clinically acceptable agreement limit was arbitrarily set at $2.5 \mathrm{~mm}$ and $\alpha=0.05$.

The relationship between US and CT measurements was evaluated by the Pearson's correlation coefficient. In addition to the Bland-Altman analysis, a paired Student's t-test was performed to assess the comparability of the two imaging modalities, and the Shapiro-Wilk test was used to assess normal distribution.

The sensitivity and specificity of CT for detection of intraluminal fluid and intramural cystic lesions were also calculated using US as the gold standard. 


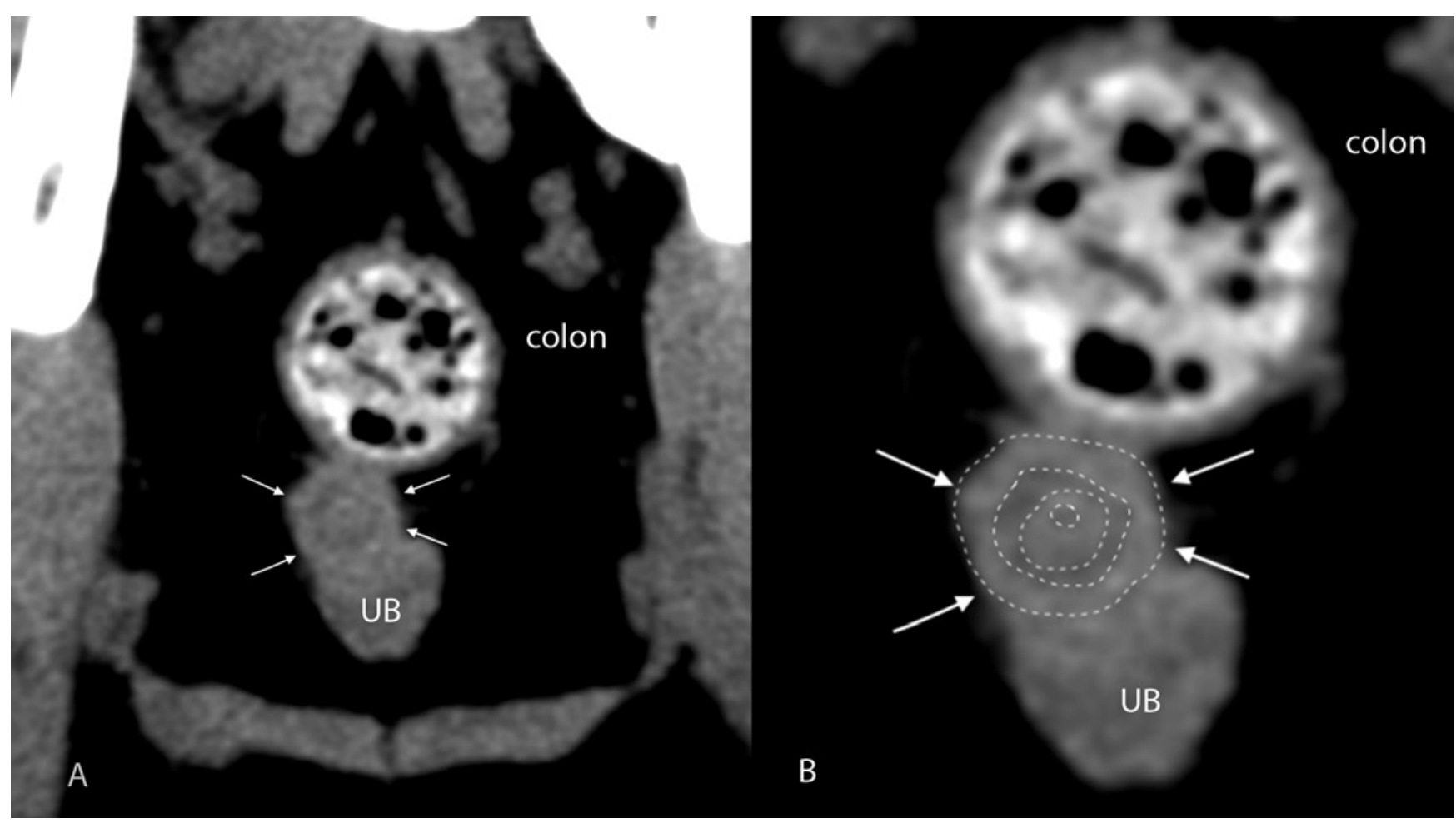

Figure 2. Native computed tomography at the level of the cervix (transverse plane). The cervix is located between the colon and the urinary bladder (UB) and is indicated by the white arrows. Panel B. is a close up of panel A. with differently attenuated areas highlighted by dotted lines. These may relate to anatomical wall segments from center to periphery: hypoattenuated lumen, thick bandlike hyperattenuated region endometrium, hypoattenuated inner muscular layer, and more hyperattenuated outer muscular layer.

To eliminate interobserver variability, a single staff member (S.V.) performed all CT and US measurements. All data of each imaging modality was assessed consecutively with the second imaging modality assessed in a blinded manner to the first imaging modality.

\section{RESULTS}

\section{Sample size calculation}

Based on the established criteria $(\alpha=0.05, \beta=$ 0.10 and clinically acceptable agreement at $2.5 \mathrm{~mm}$ ), the sample size required to provide $90 \%$ power in assessing agreement between the two methods of measurement was $\mathrm{N}=22$.

\section{Demographic data of the sample}

The 22 intact bitches included in the analysis ranged in body weight from 2.1 to $45.7 \mathrm{~kg}$ (mean \pm $\mathrm{SD}, 19.9 \pm 12 \mathrm{~kg}$ ) and from 1 to 7.5 years old (mean $\pm \mathrm{SD}, 3.8 \pm 1.8$ years). The sample included 18 different breeds (2 Swedish elkhounds, 1 Welsh Corgi Cardigan, 1 Cane Corso, 1 Border collie, 1 Pomeranian, 1 Golden retriever, 1 Chihuahua, 1 Staffordshire bull terrier, 2 Labrador retriever, 1 Shetland sheepdog, 1 Curly coated retriever, 1 Eurasier, 1 Kromfohrländer, 1 German shepherd dog, 1 Perro De Agua Español,
1 Boxer, and 1 Flatcoated retriever), and the three remaining dogs were mongrels. Reasons for referral for computed tomography included orthopedic symptoms $(\mathrm{n}=16)$, upper- and/or lower-airway symptoms $(n=4)$, neurological symptoms $(n=1)$ and ophthalmic symptoms $(\mathrm{n}=1)$. Two dogs underwent pre- and post-contrast CT imaging. All of the dogs were nulliparous.

\section{Vaginal cytology}

Vaginal cytology identified three dogs in proestrus, one dog in estrus, eleven dogs in metestrus and seven dogs in anestrus.

\section{Descriptive results}

\section{CT description}

On the native computed tomography examination, the mean cervix diameter measured $10.3 \mathrm{~mm}(\mathrm{SD} \pm$ $3.3)$ and $9.5 \mathrm{~mm}(\mathrm{SD} \pm 3.2)$ in the longitudinal and transverse planes, respectively (Table 1). In eleven of the 22 dogs $(50 \%)$, native CT revealed multiple layers of the cervix, similar in appearance to the US 'bullseye' (Figure 2). In those eleven dogs, the CT image showed three concentric rings with a hyperattenuated outer layer, a hypoattenuated middle layer and a hyperattenuated periluminal layer. Narrowing the window width and window level improved visu- 


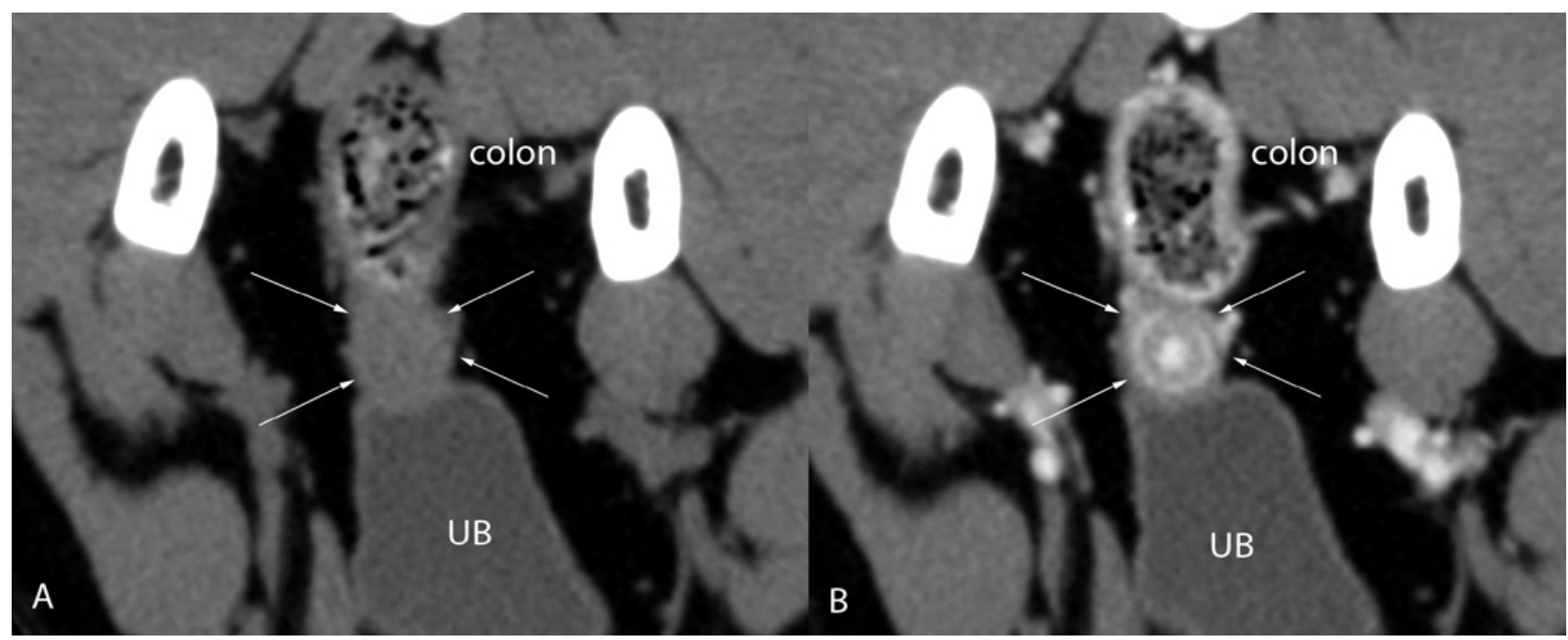

Figure 3. A. Pre and B. post contrast-computed tomography at the level of the cervix (transverse plane). Note the intense central contrast enhancement (possibly indicating mucosal enhancement) and the distinct circular enhancement (possibly representing the stratum vasculare between inner and outer parts of the muscular layer). This pattern resembles the normal cervical enhancement pattern in premenopausal women.

alization of these rings. Seven of the eleven cases exhibited an irregular hypoattenuated center of $37.9 \pm 4$ Hounsfield units (mean \pm SD), compatible with fluids such as blood, exudate or mucus, or soft tissues The remaining cervical soft tissues measured $50.9 \pm 4.2$ Hounsfield units. This ring appearance may relate to the outer longitudinal muscular layer, the inner circular muscular layer, the endometrium and the cervical lumen (not constantly content-filled), moving from the periphery to the center.

Both cases that received intravenous contrast exhibited a cervical enhancement pattern (Figure 3) with an intense central contrast enhancement that may relate to the mucosal layer (endometrium). Both cases exhibited also a second thin ring of contrast enhancement localized toward the periphery, possibly relating to the stratum vasculare located between the inner and outer muscular layers (Augsburger and Kürzi, 2004). This second ring was distinct in one dog and more diffuse in the other. As mentioned above, the cervix exhibited an irregular hypoattenuated central area. Post-contrast acquisitions revealed strong central enhancement in that area, confirming the presence of vascularized structures and not (exclusively) fluid or blood, which could be misinterpreted in the precontrast acquisition (Figure 4).

On the native $\mathrm{CT}$ acquisitions, the uterine horns appeared as tubular, slightly flattened, i.e. not rounded, attenuated soft tissue structures. Their path varied from relatively straight to moderately tortuous; a straighter path between the cervix toward both ovaries was associated with a more homogeneous appearance. Increased tortuosity was associated with increased heterogenicity of the uterus. The uterine horn size is summarized in Table 1. In all cases, the uterine horns, body and cervix could be visualized in their entirety. Fifteen dogs (68\%) exhibited a homogenous attenuation, five dogs (23\%) exhibited a heterogeneity with diffusely outlined hypoattenuated areas, and two dogs $(9 \%)$ exhibited a homogeneous hypoattenuated luminal content (HU range 11-18) consistent with uterine fluid.

The two cases that received intravenous contrast exhibited different uterine horn enhancement patterns. The first dog, a nulliparous three-year-old Pomeranian bitch with a body weight of $2 \mathrm{~kg}$ had a thin

Table 1. US and CT measurements of the uterus and ovaries, with paired differences and correlations.

\begin{tabular}{lcccc}
\hline & $\begin{array}{c}\text { Ultrasound } \\
\text { Mean (SD) }\end{array}$ & $\begin{array}{c}\text { CT } \\
\text { Mean (SD) }\end{array}$ & $\begin{array}{c}\text { Difference } \\
\text { Mean (SD) }\end{array}$ & $\begin{array}{c}\text { Pearson's Correlation } \\
\text { coefficient }\end{array}$ \\
\hline Cervix & & & \\
Longitudinal plane & $9.2(3.2)$ & $10.3(3.3)$ & $-1.1(1.7)$ & $0.86^{*}$ \\
Transverse plane & $8.4(3.1)$ & $9.5(3.2)$ & $-2.7(3.2)$ & $0.95^{*}$ \\
Body & $4.1(1.7)$ & $6.3(2.4)$ & $-2.3(1.9)$ & $0.62^{*}$ \\
Left uterine horn & $4.7(2.1)$ & $6.2(2.5)$ & $-1.5(1.3)$ & $0.85^{*}$ \\
Right uterine horn & $4.3(1.9)$ & $5.7(2.3)$ & $-1.4(1.5)$ & $0.76^{*}$ \\
Left ovary & $14.4(5.1)$ & $16.0(4.5)$ & $-1.6(3.7)$ & $0.71^{*}$ \\
Right ovary & $13.6(4.2)$ & $15.8(4.2)$ & $-2.2(3.4)$ & $0.67^{*}$ \\
\hline
\end{tabular}

Measurements were performed in the longitudinal plane, other than for the cervix ( 2 planes). All values are in millimeters. $* \mathrm{P}<0.05$. 


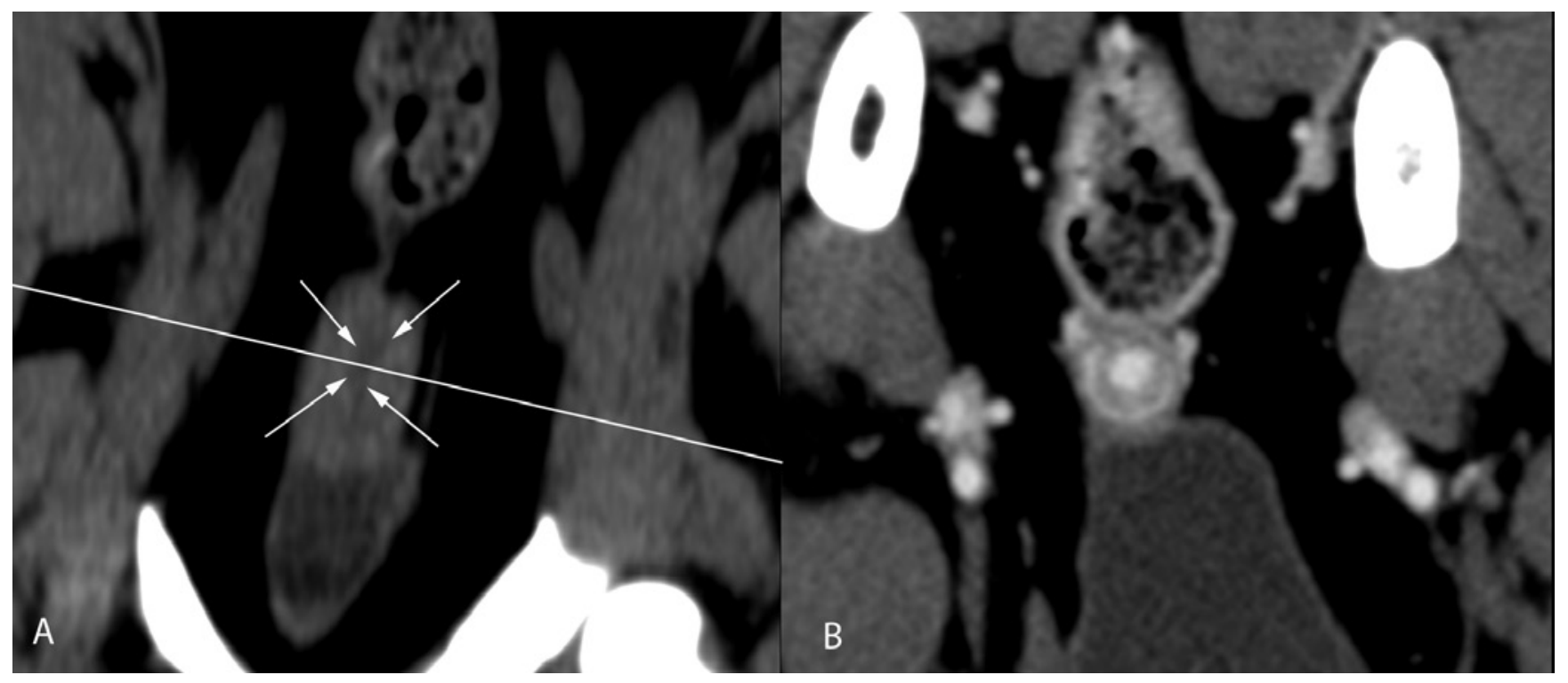

Figure 4. A. Native dorsal CT reconstruction at the level of the cervix showing an elongated central hypoattenuated area (arrows). This area shows intense contrast enhancement (B. transverse plane). This area could be misinterpreted as fluid on a native computed tomographic study.

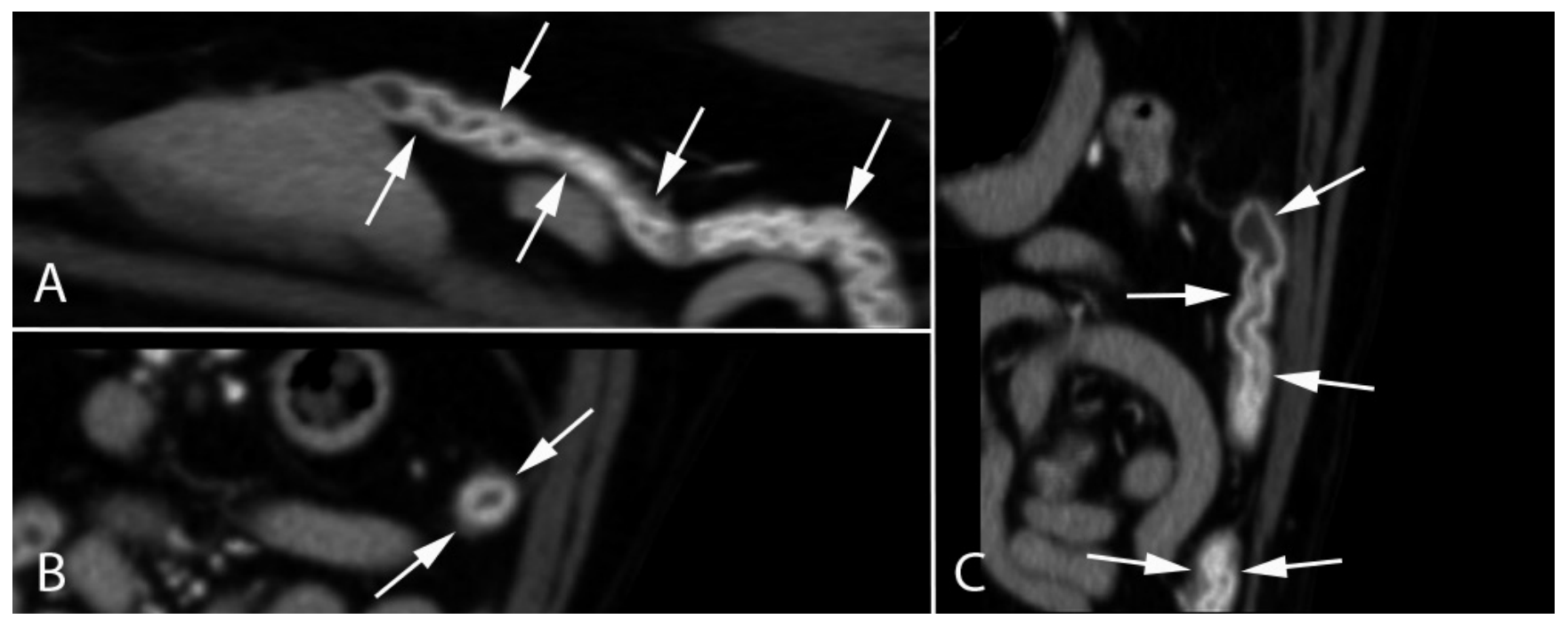

Figure 5. Multiplanar reconstruction with A. sagittal, B. transverse and C. dorsal plane of post-contrast CT in a threeyear-old Golden retriever. Note moderately tortuous uterus with marked mural enhancement and subsequently distinct uterine lumen containing hypoattenuated fluid (HU 14-18).

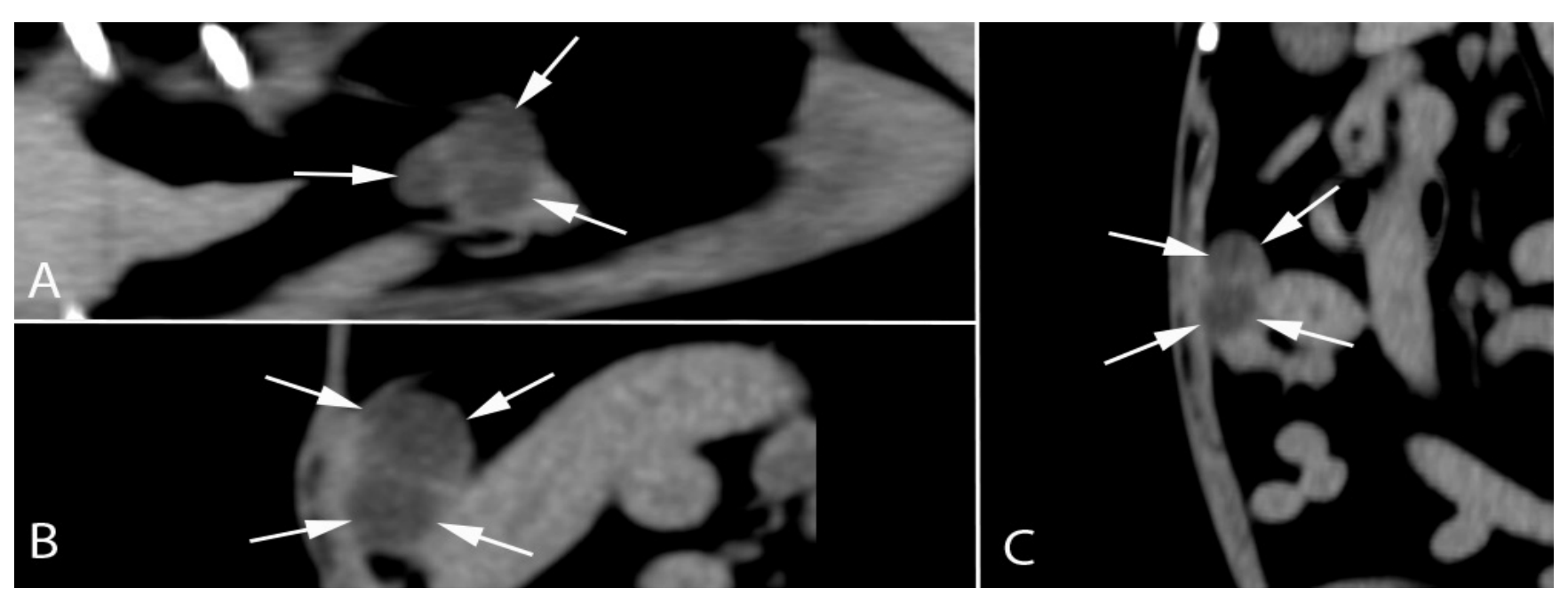

Figure 6. Multiplanar reconstruction of native CT with A. sagittal, B. transverse and C. dorsal plane centered on right ovary with lobulated appearance and three hypoattenuated areas (arrows). 

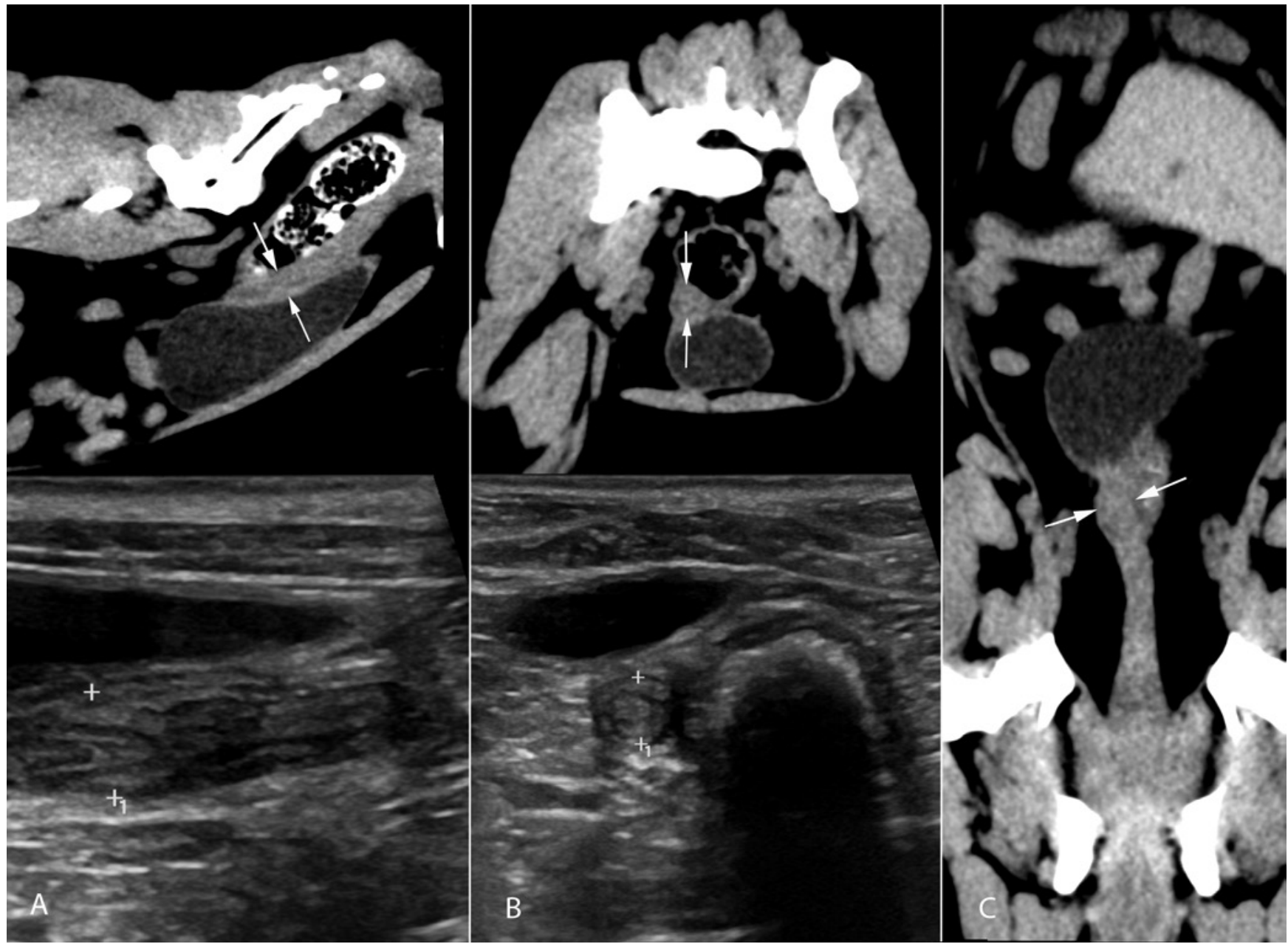

Figure 7. CT multiplanar reconstruction of native CT with A. sagittal, B. transverse and C. dorsal planes. A. and B. The corresponding ultrasound images with bullseye appearance are also shown.

and relatively straight uterine horn (approximately 1.5 $\mathrm{mm}$ in diameter). Contrast enhancement was moderate, homogeneous and generalized. In the second case, a three-year-old nulliparous Golden retriever bitch with a bodyweight of $27.5 \mathrm{~kg}$, there was mild presence of intraluminal fluid (HU 14-18) in the moderately tortuous uterine horns (approximately $7 \mathrm{~mm}$ in diameter). In post-contrast images, marked enhancement of the inner part of the uterine horn wall revealed a distinct lumen and hypoattenuated fluid (Figure 5). According to the vaginal cytology data, both dogs were in metestrus.

On the native $\mathrm{CT}$ acquisitions, the ovaries varied in size (Table 1), shape and presence of hypoattenuated areas. A sizeable majority $(89 \%)$ was oval in shape, with a smooth to mildly bumpy surface. Only five ovaries (11\%) had a clearly lobulated appearance with one or more visibly hypoattenuated regions (HU 13-18), possibly indicating cyst-like structures (Figure 6). In the first bitch receiving intravenous contrast, ovarian contrast enhancement was mild to moderate and homogeneous in character. In the second bitch receiving intravenous contrast, contrast enhancement was mild and more heterogeneous.

\section{US description}

The diameter of the cervix, uterine corpus and both uterine horns as well as the length of the ovaries are summarized in Table 1. Thirteen dogs exhibited a cervix with prominent multiple layers and bullseye appearance (Figure 7). In six dogs, ultrasonography revealed a thin intraluminal hyperechoic line. Five dogs had small amounts of anechoic luminal fluid. Cystic changes of $1-2 \mathrm{~mm}$ in size in the uterine wall were observed in four dogs, with all of them also exhibiting a subjectively thickened uterine wall, consistent with cystic endometrium hyperplasia. Thirteen ovaries had cyst-like structures.

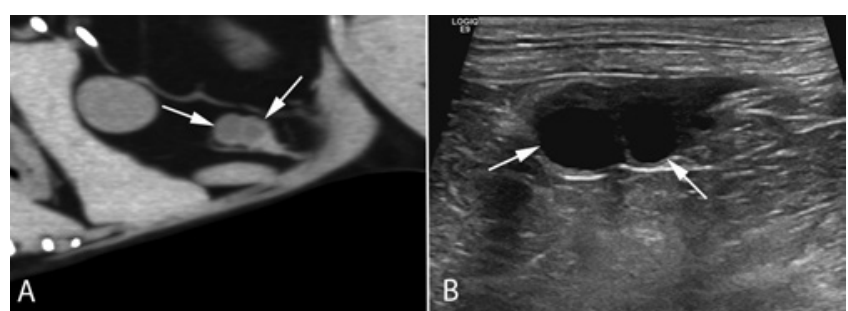

Figure 8. US and CT of the same ovary, showing round anechoic and hypoattenuated regions, respectively. 


\section{Comparison of CT and US findings}

Of thirteen dogs exhibiting a cervix with prominent multiple layers and bullseye appearance on US examination, eleven (sensitivity of $85 \%$ ) looked similar on CT. The transverse plane proved most useful for evaluation of this region, followed by the dorsal plane (Figure 7). The two false negative cases, i.e. bullseye on US but not on CT, exhibited a swollen cervix without concentric rings of different attenuation. CT imaging returned no false positives for bullseye appearance (100\% specificity). According to vaginal cytology data, these eleven dogs were at different stages of the estrus cycle, with one in proestrus, six in metestrus, and four in anestrus. The two false negative cases were in proestrus and estrus, respectively.

In six dogs, US revealed a thin intraluminal hyperechoic line that could not be detected in any case using CT. Based on CT, one of those six dogs was thought to have intraluminal fluid.

According to US, five dogs had small amounts of anechoic luminal fluid, which CT revealed only in three out of these five cases.

Cystic changes of 1-2 $\mathrm{mm}$ in size in the uterine wall were observed by US in four dogs that also appeared to exhibit a thickened uterine wall, consistent with cystic endometrium hyperplasia (Bigliardi et al., 2004).

Native CT could not identify any cystic change but revealed mild enlargement of the uterus in the same four dogs (diameters $11 \mathrm{~mm}, 5.2 \mathrm{~mm}, 10.2 \mathrm{~mm}$, and $9.5 \mathrm{~mm}$ in dogs weighing $13.6 \mathrm{~kg}, 4.7 \mathrm{~kg}, 24.7 \mathrm{~kg}$, and $29.4 \mathrm{~kg}$, respectively). Additionally, a more tortuous uterine path and heterogeneous attenuation with diffusely delineated areas of hypoattenuation were thought to possibly indicate small areas of intraluminal fluid. According to vaginal cytology data, all four of those dogs were in metestrus. This CT appearance was yet seen in a dog (being in estrus), in which US did not detect cystic lesion.

In relation to the detection of cyst-like structures in the ovaries, native CT achieved 38\% sensitivity and $100 \%$ a specificity, detecting five of thirteen ovaries detected by US (Figure 8). The eight false negatives had cyst-like structures areas equal in or smaller than $3.5 \mathrm{~mm}$ in diameter. No false positive cases were noted.

\section{Statistical results}

Statistical analysis confirmed normal distribution of the data. A moderate to strong correlation was observed between all CT and US measurements (Table $1)$. The strongest correlation (0.86 for longitudinal plane and 0.95 for transverse plane) was for the cervix, and the weakest correlation (0.62) was for the corpus. All mean values were consistently higher on CT than on US.

The paired t-test showed no statistical agreement between US and CT measurements, with $\mathrm{P}<0.05$ for all areas. According to the Bland-Altman plots, differences for all areas exceeded the predetermined acceptable agreement limit of $2.5 \mathrm{~mm}$.

\section{DISCUSSION}

Computed tomography successfully visualized the uterus and ovaries of 22 bitches with no clinical signs of urogenital organ disease. The observed variability of appearance is thought to relate to the sample's heterogenicity in terms of size, age and stage of the estrus cycle, all of which are known to influence the appearance of both organs (Silva et al., 1996; England et al., 2003; Davidson and Baker, 2009; Pollard and Hecht, 2015).

Native CT identified a cervix with bullseye appearance (involving three distinct concentric rings and variable presence of a hypoattenuated lumen) with $85 \%$ sensitivity and $100 \%$ specificity. Contrastenhanced acquisitions in two of the 22 dogs achieved better delineation of the uterine lumen, resulting in better detection of intraluminal fluid or cystic mural lesions. Both of those dogs showed the same pattern of thick central enhancement and thin peripheral ring enhancement. This is not unlike the equivalent in pre-menopausal women, which has been reported as a thin or thick bandlike enhancement outlining the endometrial canal, with or without a thin outer myometrial enhancement (Yitta et al., 2011). More diffuse myometrial enhancement has also been observed in both pre- and post-menopausal women. This variability in enhancement pattern probably relates to multiple factors, including stage of the menstrual cycle, variable anatomic blood supply, timing of acquisition and patient age (Yitta et al., 2011). As both dogs in the present study were nulliparous and in metestrus at the time of CT acquisition, it is unclear whether this enhancement pattern relates specifically to the stage of the estrus cycle and the number of previous pregnancies. It seems likely that the canine uterus also exhibits other patterns of normal enhancement; for instance, multiparous dogs with larger and more numerous blood vessels in the stratum vasculare are likely to exhibit more diffuse or increased enhancement than nulliparous dogs (Augsburger and Kürzi, 2004). CT angiography of larger samples will be required to confirm and further elucidate this effect.

Native computed tomography was not sufficiently sensitive to detect cystic lesions in the uterine wall. These lesions indicate cystic endometrium hyperplasia $(\mathrm{CEH})$, a common disease affecting middle aged bitches that may relate to prolonged progesterone stimulation during the luteal phase. Often diagnosed incidentally, this may contribute to infertility, and secondary bacterial infections can cause pyometra (England et al., 2003; Bigliardi et al., 2004). In the present study, US revealed signs of CEH in four dogs. Although native CT failed to detect these cysts, other 
abnormalities were observed, including mild enlargement and increasing tortuosity of the uterus, as well as increased heterogenicity of the uterus with hypoattenuated areas. Detection of these concomitant changes should alert clinicians to the possibility of $\mathrm{CEH}$, warranting ultrasonographic examination. Native CT sensitivity to cyst-like structures in the ovaries was also low, with false negatives for cyst-like structures of 3.5 $\mathrm{mm}$ diameter or smaller on US images. As in the case of uterine cysts, the small size of these lesions may have hampered CT detection. The possible superiority of contrast-enhanced CT over native CT for the detection of cystic changes in either the uterine wall or the ovaries could unfortunately not be assessed as none of both bitches that had a contrast-enhanced CT, showed ultrasonographic signs of cystic changes.

The moderate to strong correlation between ultrasound and $\mathrm{CT}$ measurements suggests that $\mathrm{CT}$ uterine and ovarian measurements approximate US. CT measurements were systematically higher than US. However, the hypothesized equality between the two had to be rejected, most likely secondary to a lack of standardized position for the measurements of the uterus because of its frequent contact with other abdominal organs that hampered accurate measurement in both modalities. The measurements were furthermore complicated by the frequently tortuous path of the uterus. The rejection of this hypothesis aligns with multiple studies performed in human medicine that have also reported differences between US and CT measurements (Singh et al., 2004; Manning et al., 2009, Han et al., 2010). As one example, Singh et al. reported that normal aortas are measured as larger in diameter when measured by CT. Studies in which the diameter of aneurysmal aortas are analyzed in humans are inconsistent, returning both larger and smaller diameters when measured by CT (Singh et al., 2004; Manning et al., 2009). Computed tomography also overestimates esophageal tumor length in human medicine (Sillah et al., 2010). The exact cause of the discrepancy is unknown but most likely multifactorial, and causes as motion artifacts, partial volume effect, difficulties to differentiate tumoral from peritumoral fibrotic tissues, interobserver variability and tortuosity of the regions of interest are proposed (Singh et al., 2004; Sillah et al., 2010)

One limitation of the present study is the heterogenicity of the group. In combination with the relatively small sample size, this prevents multivariate statistical analysis. It therefore remains unclear whether, in what way and to what extent the estrus cycle, previous pregnancy, age or other variables might influence CT measurement of the uterus and ovaries. Secondly, serum concentrations of progesterone and estradiol would have been complementary in the assessment of the stage of the estrus cycle as estrus cycling staging solely based on vaginal cytology can be challenging (Arlt, 2018). Thirdly, the majority of the included dogs did not receive intravenous contrast administration.
This was the authors deliberate choice to reflect the daily practice at the institution where the vast majority of the orthopedic CT examinations are performed without intravenous contrast administration. This is reflected in the present study as 16 out of the 22 included bitches were referred for orthopedic diseases with all of them only having a native CT examination. Finally, the sensitivity and specificity calculations deferred to ultrasonography as the gold standard. Although US is routinely used for evaluation of the urogenital tract, quality and detection level are influenced by the equipment, the patient's size, the adequacy of patient preparation, and the sonographer's level of experience, introducing the risk of error in relation to sensitivity and specificity.

\section{CONCLUSION}

The uterus and ovaries of bitches with no clinical signs of urogenital disease can be assessed using computed tomography. The present study described and illustrated a range of cervical, uterine horn and ovarian appearances. Neither organ should be overlooked during non-urogenital examination of native or contrast-enhanced $\mathrm{CT}$ acquisitions, which can provide valuable information about issues such as intraluminal uterine fluid or characteristic features of cystic endometrium hyperplasia. Additional studies describing uterine contrast enhancement in larger groups will be needed to further clarify the spectrum of normal and abnormal CT appearance and the effect of variables, such as the stage of estrous cycle, age, and previous pregnancy. Assessment of uterine and ovarian size by computed tomography resulted in systematic differences as compared to US assessments. Nevertheless, the observed moderate to strong correlations between the two modalities suggest that CT measurements can be used as an approximation of US measurements.

\section{ACKNOWLEDGEMENTS}

The study was funded by Stiftelsen Strömsholm Djursjukvård.

\section{LITERATURE}

Arlt S., Haimerl P. (2016). Cystic ovaries and ovarian neoplasia in the female dog - a systematic review. Reproduction in Domestic Animals 51 (suppl 1), 3-11.

Arlt S. (2018). Canine ovulation timing: A survey on methodology and an assessment on reliability of vaginal cytology. Reproduction in Domestic Animals 53 (Suppl 3), 53-62.

Augsburger H., Kürzi M. (2004). Histomorphological and morphometric evaluation of the uterine horns in nulliparous and multiparous Beagles. American Journal of Veterinary Research 65 (5), 552-558. 
Bigliardi E., Parmigiani E., Cavirani S., Luppi A., Bonati L., Corradi A. (2004). Ultrasonography and cystic hyperplasia-pyometra complex in the bitch. Reproduction in Domestic Animals 39 (3), 136-140.

Davidson A. and Baker T. (2009). Reproductive ultrasound of the bitch and queen. Topics in Companion Animal Medicine 24 (2), 55-63.

Dow C. (1959). The cystic hyperplasia-pyometra complex in the bitch. Journal of Comparative Pathology and Therapeutics 69, 237-250.

England G.C.W., Yeager A.E., Concannon P.W. (2003). Ultrasound imaging of the reproductive tract of the bitch. In: Concannon P.W., England G.C.W., Verstegen J.P., Linde-Forsberg C. (editors). Recent Advances in Small Animal Reproduction. Ithaca, NY, International Veterinary Information Service.

Evans H. and de Lahunta A. (2013). The urogenital system. In: Evans H. and de Lahunta A. (editors). Miller's Anatomy of the Dog. Fourth edition, Elsevier, Missouri, 392-393.

Freitas L.A., Mota G.L., Silva H.V.R., Silva L.D.M. (2017). Two-dimensional sonographic and Doppler changes in the uteri of bitches according to breed, estrus cycle phase, parity, and fertility. Theriogenology 95, 171-177.

Hagman R. (2014). Diagnostic and prognostic markers for uterine diseases in dogs. Reproduction in Domestic Animals 49, 16-20.

Han S., Patel K., Rowe V., Perese S., Bond A., Weaver F. (2010). Ultrasound-determined diameter measurements are more accurate than axial computed tomography after endovascular aortic aneurysm repair. Journal of Vascular Surgery 51 (6), 381-389.

Kähn W. (2004). Ultrasonography in dogs and cats. In: Kähn W. (editor). Veterinary Reproductive Ultrasonography. Schlütersche Verlagsgesellschaft $\mathrm{mbH} \&$ Co., Hannover, 227-252.

Lu M., Zhong W., Liu Y., Miao H., Li Y., Ji M. (2016). Sample size for assessing agreement between two methods of measurement by Bland-Altman method. The International Journal of Biostatistics 12 (2), 2015-0039.

Manning B., Kristmundsson T., Sonesson B., Resch T. (2009). Abdominal aortic aneurysm diameter: A comparison of ultrasound measurements with those from standard and three-dimensional computed tomography reconstruction. Journal of Vascular Surgery 50 (2), 263268.

Nyland T.G., Mattoon J.S. (2002). Ovaries and uterus. In: Nyland T.G., Mattoon J.S. (editors). Small Animal Diagnostic Ultrasound. Second edition, Philadelphia, WB Saunders, 231-249.

Poffenbarger E., Feeney D. (1986). Use of gray-scale ultrasonography in the diagnosis of reproductive disease in the bitch. Journal of the American Veterinary Medical Association 189 (1), 90-95.
Pollard R., Hecht S. (2015). Female reproductive tract. In: Penninck D. and d'Anjou M. (editors). Atlas of Small Animal Ultrasonography. Second edition, Wiley Blackwell, Iowa, 403-421.

Schummer A., Wilkens H., Vollmerhaus B., Habermehl K. (1981). Organs of the Circulation. In: Schummer A., Wilkens H., Vollmerhaus B., Habermehl K. (editors). The Circulatory System, the Skin, and the Cutaneous Organs of the Domestic Mammals. Springer, Boston, 177-266.

Sillah K., Williams L., Laasch H., Saleem A., Watkins G., Pritchard S., Price P., West C., Welch I. (2010). Computed tomography overestimation of esophageal tumor length: Implications for radiotherapy planning. World Journal of Gastrointestinal Oncology 2 (4),197-204.

Silva L., Onclin K., Verstegen J. (1996). Assessment of ovarian changes around ovulation in bitches with ultrasonography, laparoscopy and hormonal assays. Veterinary Radiology and Ultrasound 37 (4), 313-320.

Singh K., Jacobson B.K., Solberg S., Kumar S., Arnesen E. (2004). The difference between ultrasound and computed tomography (CT) measurements of aortic diameter increases with aortic diameter: analysis of axial images of abdominal aortic and common iliac artery diameter in normal and aneurysmal aortas. European Journal of Vascular and Endovascular Surgery 28 (2), 158-167.

Solano-Gallego L., Masserdotti C. (2015). Reproductive system. In: Raskin R. and Meyer D. (editors). Canine and Feline Cytology: a Color Atlas and Interpretation Guide. Thirdth edition, Elsevier, St Louis (Missouri), 313-352.

Veiga G., Miziara R., Angrimani D., Papa P., Cogliati B., Vannucchi C. (2017). Cystic endometrial hyperplasiapyometra syndrome in bitches: identification of hemodynamic, inflammatory, and cell proliferation changes. Biology of Reproduction 96 (1), 58-69.

Yeager A.E., Concannon P.W. (1995). Ultrasonography of the reproductive tract of the female dog and cat. In: Bonagura J.D. (editor). Kirk's Current Veterinary Therapy XII. Philadelphia: WB Saunders, 1040-1052.

Yitta S., Hecht E.M., Mausner E.V., Bennett G.L. (2011). Normal or abnormal? Demystifying uterine and cervical contrast enhancement at multidetector CT. Radiographics 31 (3).

\section{c) creative} distributed under the terms and conditions of
the Creative Commons Attribution (CC BY) license (http://creativecommons.org/licenses/by/4.0/).
(C) 2021 by the authors. Licensee Vlaams Diergeneeskundig Tijdschrift, Ghent University, Belgium. This article is an open access artic 